\title{
The Influence of Different Types of Wind Farm on the Voltage Characteristics of Grid Side
}

\author{
C. LIANG, L. MA, T.LIU \& H.C. DAI \\ State Grid Energy Research Institute, Beijing, China
}

\begin{abstract}
Key words: Wind Farm; Voltage Characteristics; voltage deviation; Fixed-speed wind turbin; Variable-speed wind turbine

Abstract: The theory of power qualities such as voltage deviation, voltage fluctuation and harmonic caused by wind power farms composed by different wind turbine is revealed in this paper. Based on PSCAD/EMTDC, fixed-speed wind turbine wind farm power quality characteristics of power grid side simu-lation model that can switch reactive power compensation device, and variable-speed wind turbine wind farm power quality characteristics simulation model that can operate under constant power factor or given reactive power are built respectively. Simulation analysis on the grid side voltage deviation, voltage fluctuations and harmonic characteristics show that, fixed-speed wind turbine wind farm affect voltage deviation and voltage fluctuation significantly, variable-speed wind turbine wind farm have little effect on voltage deviation and voltage fluctuation but cause serious effect on harmonic pollution. The research will be of huge significance for power quality management in wind farm or regional power grid and power quality management strategy research for different wind turbine farm.
\end{abstract}

\section{Introduction}

Wind power use wind as power source, due to the variable characteristics of wind energy, mechanism structure of wind turbine and the characteristics spatial and temporal distribution of wind speed and wind direction, large scale wind power integrate into the power grid will have a serious impact on the power quality of the power grid, such as voltage fluctuation caused by wind power output, wind shear, voltage fluctuation and flicker caused by tower shadow effect, harmonic wave caused by variable speed wind turbine generator and other issues (Gao, 2010; WU, 2008; SUN, 2003; WU, 2009). At present, the wind turbine operating in China can be divided into two categories including the constant speed and propeller type and the variable speed and propeller type (LIU, 2009), among them the capacity of variable speed and variable propeller wind turbine is usually more than $1 \mathrm{MW}$, and they are currently the mainstream wind turbine products, the constant speed and propeller wind turbines are early products, the capacity is usually less than the MW level, the power is mainly $600 \mathrm{~kW}$ or $750 \mathrm{~kW}$. Because of the different structure and working principle, the influences of different types of wind farm on power quality are different, therefore, it is necessary to systematically analyze the influence of the wind farm on the power quality of the two types of wind turbines, and provide a theoretical basis for the power quality control of wind farm (CHI, 2007; HU, 2009; HUANG, 2012).

In this paper, therefore, we take the variable speed unit and the constant speed unit as the basic classification of wind turbine type. Firstly, we reveal the principle of voltage deviation and voltage fluctuation of different types of the wind farm from the mechanism, and then we set up the constant speed of wind turbine and variable speed of wind turbine simulation model of power quality characteristics based on the PSCAD/EMTDC, finally we carried out the simulation analysis on the problem of voltage deviation and voltage fluctuation caused by the constant speed turbine or variable speed turbine and get the conclusion that the influence of wind farm on the grid characteristic of different wind turbine types. 


\section{Principle of voltage control problem caused by wind farm}

\subsection{Principle of voltage deviation caused by wind farm}

In the power system, the load increase or decrease, the generator output exchange, the grid structure change and other factors can cause the system power imbalance, which means there will be a lot of power flow through the transmission line and transformer. Because of the impedance of the circuit and the transformer, there is a difference between the first and terminal voltage of the line and transformer, which is the root cause of the system voltage deviation. The equivalent circuit diagram and phase diagram of voltage deviation caused by wind farm integration are shown in Fig.1 and Fig.2.

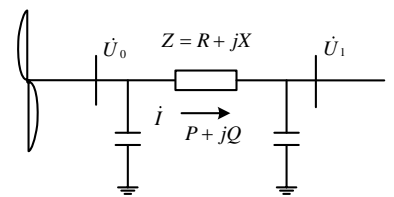

Fig.1. Simplified Equivalent Circuit of

Wind Farms

Integration.

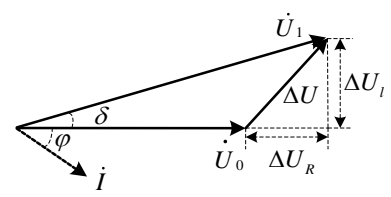

Fig.2. Simplified

Equivalent Phasor

Diagram of Wind

Farms Integration

In Fig.1, the wind farm is connected to the power grid through the transmission line (equivalent resistance $\left.^{Z}=R+j X\right), \dot{U}_{0}$ and $\dot{U}_{1}$ are power grid voltage and high-pressure side end voltage of wind farm respectively. When the wind farm is running, the active power is sent to the system $(P>0)$, and the voltage drop on the outlet of the wind farm is:

$$
\Delta U=\frac{P R+Q X}{U_{1}}+j \frac{P X-Q R}{U_{1}}
$$

The pressure drop on the line can be divided into the longitudinal components $\Delta U_{R}$ and the transverse components $\Delta U_{1}$ by the phases diagram analysis of Fig.2., due to the phase-angle difference of the line is small, the transverse component $\Delta U_{1}$ can be neglected, then the voltage drop can be regarded as the longitudinal component $\Delta U_{R}$,

$$
\Delta U=\frac{P R+Q X}{U_{1}}
$$

In the high voltage power transmission network, $X>>R$ therefore, the influence of reactive power $\mathrm{Q}$ on the voltage drop is much greater than that of the active power $\mathrm{P}$. If you do not consider the effect of distribution capacity, wind farm is composed of constant speed wind turbine, when the output of active power $\mathrm{P}$ growth, the absorption of reactive power $\mathrm{Q}$ growth, meanwhile, the growth of active power output of the line will lead to reactive power consumed by the line reactance increase, when the $\mathrm{PR}+\mathrm{QX}>0$, the wind farm voltage ${ }^{U_{0}}$ will be less than the power grid voltage ${ }^{U_{1}}$. The wind farm, which is composed of a variable speed unit, can realize the decoupling control of active power and reactive power, so the wind farm and the power grid does not exchange reactive power, but when the output of the variable speed unit is higher, the reactive power consumed on the line due to the active power transmission may also cause voltage drop. Considering the influence of the distribution capacitance of the circuit, when the wind farm is stopped or the output is low, the capacitive charging power of the line will cause the wind farm voltage higher than the power grid voltage. 


\subsection{Principle of voltage fluctuation caused by wind farm}

From the formula (1), we can see that when the power output of the wind turbine fluctuates, will cause the wind turbine terminal voltage $U_{0}$ and the wind farm voltage $U_{1}$ fluctuation, thus cause the grid voltage fluctuation, when the fluctuation of the output power of wind turbine is larger, even the flicker phenomenon can be caused. In addition, from the expression of the mechanical power of the wind turbine, we can know (LOU, 2007),

$$
P=0.5 \rho C_{p}(\lambda, \beta) A v^{3}
$$

In the formula, $\mathrm{P}$ is power, $\mathrm{W}, \rho$ is air density, $\mathrm{kg} / \mathrm{m}^{3}, \mathrm{~A}$ is blade sweep area, $\mathrm{m}^{2}, \mathrm{v}$ is wind speed, $\mathrm{m} / \mathrm{s}, \mathrm{CP}$ is wind energy utilization coefficient, according to Betz theory, its theoretical maximum is 0.593 , is a function of the pitch angle $\beta$ and tip speed ratio $\lambda$. The definition of tip speed ratio $\lambda$ is as follows,

In the formula, $\omega$ is impeller speed, $\mathrm{rad} / \mathrm{s}, \mathrm{R}$ is impeller radius, $\mathrm{m}$.

$$
\lambda=w R / v
$$

From the formula (3), we can know that the output of wind turbine is related to wind speed and air density. The change of the output power of wind turbine is fluctuating between zero power and rated power. Reactive power absorbed by the constant speed wind turbine varies with the output of the active power, causing the large change of the grid voltage, however, the variable speed wind turbines are usually controlled by constant power factor control mode, so the reactive power fluctuation is relatively small.

In addition, the factors that cause the output power fluctuation of wind turbine are also including the influence such as tower shadow effect, yaw error and wind shear and other factors. The torque of the impeller in the rotating progress is not stable, so that the output power of wind turbine generator is fluctuating. Typical switching operations including the start and stop of wind turbine and the generator switching, these switching operations can cause power fluctuations, and further cause voltage fluctuations and flicker of wind turbine generators and other vector nodes.

\section{Simulation model of wind farm for different types of wind turbines}

According to the above analysis, the power quality characteristics of wind farm are also affected by wind turbine type, wind turbine structure and wind speed and other aspects, and also affected by the influence of the structure parameters of the access grid. In order to further study the effects of different wind turbine types on the power quality of the grid side. This section is based on the PSCAD/EMTDC, which were established for simulation analysis model of the fixed speed wind turbine and variable speed wind power quality characteristics, and simulated and analyzed the power quality problems caused by grid connected wind farm. The simulation system of constant speed wind turbine model is as shown in Fig.3.

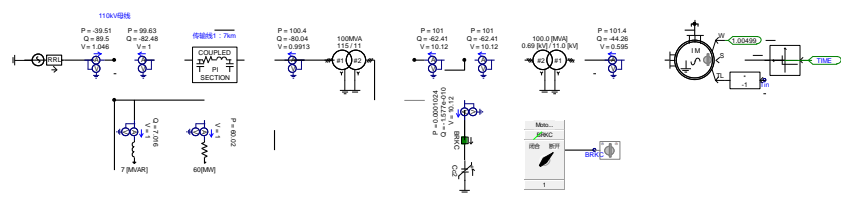

Fig.3. Fixed-speed wind turbine wind farm power quality characteristics simulation model.

Design of wind farm capacity is $105 \mathrm{MVA}$, equivalent to 140 fixed speed wind turbines whose capacity is $0.75 \mathrm{MVA}$. The rated voltage of the wind turbine is $690 \mathrm{~V}$, through the $0.69 \mathrm{kV} / 11 \mathrm{kV}$ boost transformer access to $11 \mathrm{kV} / 115 \mathrm{kV}$ main boost transformer of the wind farm. The constant speed wind turbine are equipped with capacitive compensation, therefore, this simulation can also add a compensation capacitor which can be switched according to the required reactive power. The torque of the constant speed wind turbine can be controlled, and the torque is influenced by the change of 
wind speed, so the power quality characteristics of the wind turbine can be simulated and analyzed under the condition of gust wind, noise wind and ramp wind.

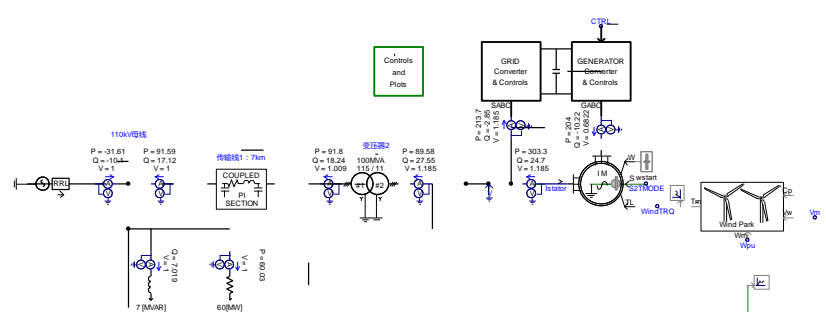

Fig.3. Variable-speed wind turbine wind farm power quality characteristics simulation model.

The model of variable speed wind turbine simulation system is shown in Fig.4. Because the voltage and reactive power characteristics of the direct drive permanent magnet synchronous wind generator is the same as that of the doubly fed induction generator with the same control target, this paper only takes the doubly fed wind turbine as the analysis object. Setting the wind farm capacity is 140MVA, equivalent to 70 double fed wind turbines whose capacity is $2 \mathrm{MVA}$. The simulation model can be used to achieve constant reactive power control and constant power factor control, but it cannot be controlled by variable pitch control. At the same time, it can also be used to analyze the power quality characteristics of wind turbine under condition of gust wind, noise wind and ramp wind.

The system conditions of the two types of wind farm accessed are same, and they are all $110 \mathrm{kV}$ system bus connected with the load of $60 \mathrm{MW}+\mathrm{j} 7 \mathrm{MV}$ ar. In order to eliminate the influence of system parameters on wind turbine power quality characteristics, the simulation set of short circuit capacity is large, equivalent to the ideal power source.

\section{Simulation and analysis of power quality on the side of wind farm}

\subsection{Simulation and analysis of voltage deviation characteristics of wind farm}

\section{A. Analysis of The constant speed wind turbine wind farm voltage deviation}

Under the influence of the basic wind, the constant speed wind turbine unit in different power exchange reactive power condition with the power grid and the changes of $110 \mathrm{kV}$ voltage are as shown in Fig.5. The Fig.5-1 is constant speed wind field without any compensation device, and the Fig.5-2 is the constant speed wind field adding compensation equipment.

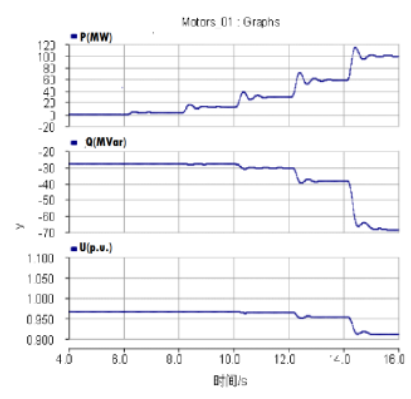

Fig.5-1 Voltage deviation of fixedspeed wind turbine wind farm with no compensation capacitor.

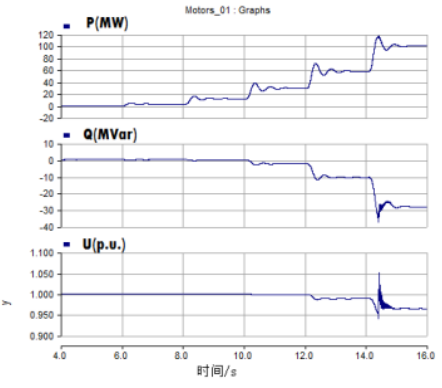

Fig.5-2 Voltage deviation of fixedspeed wind turbine wind farm with compensation capacitor. 
From the Fig.5-1., we can see that when the output power of the wind farm is less than $30 \%$ of the maximum output, the reactive power exchange rate changes little with the wind farm output, which is basically maintained at about $31 \mathrm{MVar}$, and when the wind power is $30-60 \%$, the reactive power absorbed by the wind farm is increased to $40 \mathrm{MVar}$ with the output of the active power and reactive power of wind farm increasing; when the wind power is more than $60 \%$, the amount of reactive power absorbed by the wind farm increases rapidly to $70 \%$ with the increase of the active power output. At the same time, the network side $110 \mathrm{kV}$ voltage standard values down from 0.96p.u.when the output is less than $30 \%$ to 0.95p.u.when output is $60 \%$, and then dropped to 0.91p.u.when the output $80 \%$.

Wind turbine input 30MVar compensation capacitor when the output is below $60 \%$ and input 40MVar compensation capacitor when the output is above $80 \%$. From Fig.5-2., when the output of constant speed wind field with compensation device is more than $60 \%$, the reactive power exchange capacity of the grid and the wind farm has been significantly reduced, the corresponding $110 \mathrm{kV}$ side voltage value is maintained at about 0.97 p.u.

\section{B.Analysis of the voltage deviation characteristics of the wind farm of variable speed wind turbine}

Doubly fed variable speed wind turbine can realize constant reactive power control or constant power factor control, so it is not necessary to install any reactive power compensation device. By using constant power factor control and constant reactive power control, in the case that the wind farm output active power changing, the variation curves of active power, reactive power and voltage of the boost transformer 110kV side are shown in Fig.6., where the Fig.6-1 is the variation of voltage deviation under constant power factor control, and the Fig.6-1 is the variation of voltage deviation under the control of reactive power.

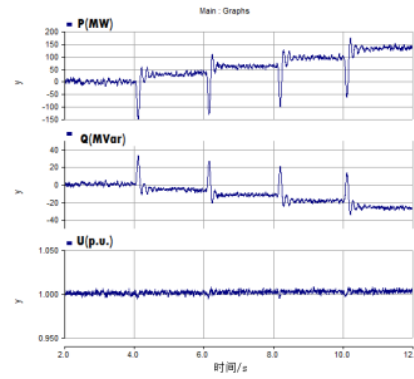

Fig.6-1 Voltage deviation of variablespeed wind turbine wind farm under constant power factor control.

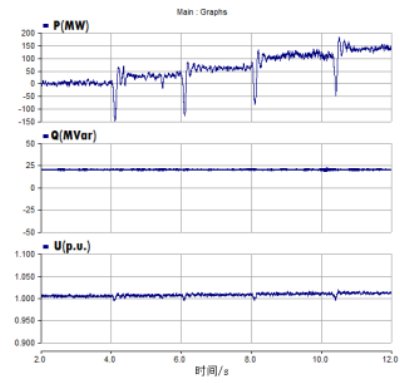

Fig.6-2 Voltage deviation of variablespeed wind turbine wind farm under given reactive power cotrol.

From the Fig.6-1 we can see that when the wind power unit adopts constant power factor control, the reactive power absorbed by the wind field increases with the increase of the output power, but due to the large power factor, The voltage of wind power booster transformer $110 \mathrm{kV}$ side bus and the system bus voltage after $7 \mathrm{~km}$ transmission line can be kept at about 1.0p.u. From Fig.6-2 we can see that when the wind turbine is controlled by reactive power control, the reactive power can be kept unchanged when the output of the wind turbine is active, so as to ensure the system side bus voltage can be basically constant at about 1.0p.u. It can be seen that doubly fed variable speed wind turbines can be flexible to achieve constant reactive power (lead and lag) and constant power factor control, so it has little influence on the voltage deviation of the power grid. 


\subsection{Simulation and analysis of voltage fluctuation characteristics of wind farm}

\section{A. The voltage fluctuation of wind farm of constant speed wind turbine}

From the 1.2 section, it can be known that wind speed is the main cause of the voltage fluctuation and flicker characteristics of the wind turbine. The changes of active power, reactive power output of the wind farm composed of fixed speed wind machine under the condition of gust wind, gradient wind, interference wind and hybrid wind and 110kV side bus voltage are shown in Fig.7.

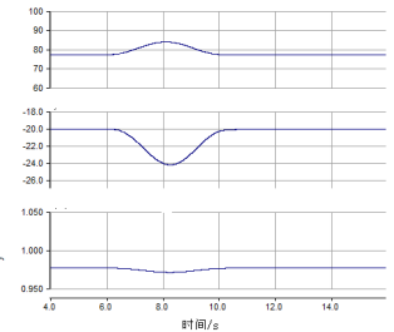

(a) Gust

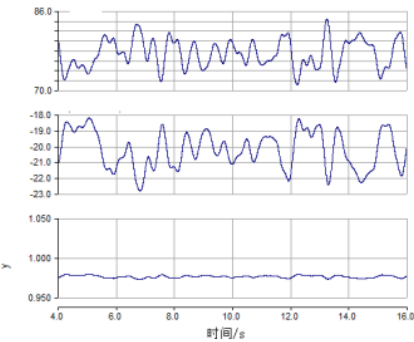

(c) Interference wind

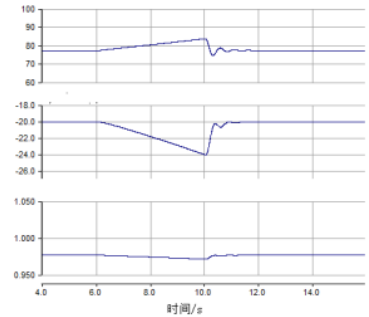

(b) Gradient wind

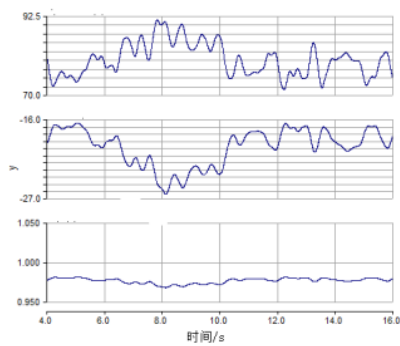

(d) Hybrid wind

Fig.7. Voltage fluctuation of fixed-speed wind turbine wind farm under four wind types.

From the Fig.7 we can see that the wind farm consists of fixed speed wind turbine will generate a voltage fluctuation in different degree under four kinds of wind speed disturbance, and the fluctuation characteristic is directly related to the fluctuation characteristics of wind speed.

\section{B. Wind farm voltage fluctuation characteristics of variable speed wind turbine}

In view of the fact that most of the doubly-fed variable speed wind turbines use constant power factor control mode, the voltage fluctuation characteristics of the wind farm of variable speed wind turbine are controlled by the constant power factor. The changes of active power, reactive power output of the wind farm composed of variable speed wind machine under the condition of gust wind, gradient wind, interference wind and hybrid wind and $110 \mathrm{kV}$ side bus voltage are shown in Fig.7. 


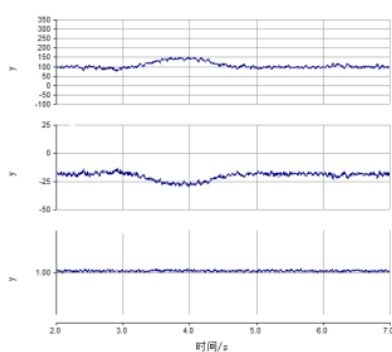

(a) Gust

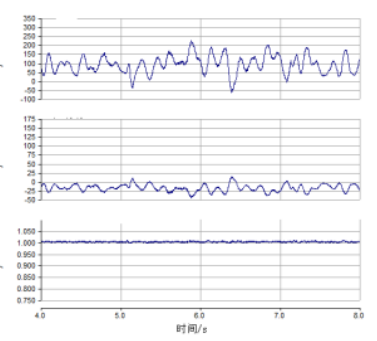

(c) Interference wind

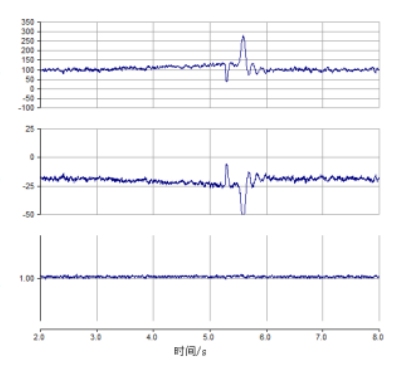

(b) Gradient wind

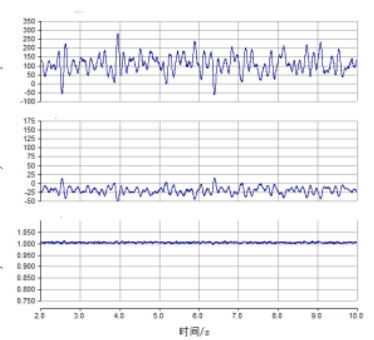

(d) Hybrid wind

Fig.8. Voltage fluctuation of variable speed wind turbine wind farm under four wind types.

From the simulation results of Fig. 8 we can know that due to the variable speed wind turbines can take the operation of constant power factor, the change of wind speed has little effect on the side voltage of the wind farm which is composed of variable speed wind turbines. And under the disturbance of four kinds of wind speed, the voltage value of the $110 \mathrm{kV}$ network can be maintained at about 1.0p.u.

\section{Conclusion}

On the basis of analyzing the principle of voltage deviation, voltage fluctuation and harmonic and so on, this paper establishes a simulation model to study the influence of the type of wind farm on the power quality of the grid. Through the simulation verification of the wind on the constant speed wind turbine and variable speed wind turbine, the conclusions are as follows.

On the condition that the constant speed wind turbine wind farm without any compensation device, the voltage deviation of the network side is greatly influenced by the wind power output, especially when the wind power output more than $60 \%$, the reactive power of the wind farm is increasing rapidly with the wind power output, and the corresponding network side voltage drop is also very obvious. After adding the reactive power compensation device, the voltage drop can be reduced to a certain extent, and the voltage stability of the network side is stable at the national standard level. Wind farm of variable speed wind turbine can be controlled by constant power factor and constant reactive power control, so the voltage deviation of the network side is not affected by the wind power output.

Under the disturbance of gust wind, gradient wind, interference wind and hybrid wind, the constant speed wind turbine wind farm will produce different levels of voltage fluctuations, and the fluctuation characteristic is directly related to the fluctuation characteristics of wind speed. Because the variable speed wind turbine is operated by the steady power factor, so the change of wind speed has little effect on the voltage fluctuation of the wind farm which is composed of variable speed wind turbines, and the $110 \mathrm{kV}$ network side voltage value can be maintained at around 1.0p.u.

The research results of this paper can provide a theoretical basis for the research of power quality control of wind farm and grid connected area, and according to different types of wind farm to develop the corresponding power quality control strategy 


\section{References}

[1] Gao Xiuying. On the Issue of the Quality of Power and the Measures of Improvement [J]. Applied Energy Technology, 2010, 4: 41-45

[2] WU Qiong. Studies on the effects of wind power farm on power quality [D]. Nanchang: Nanchang University, 2008.

[3] SUN Tao, WANG Wei-sheng, DAI Hui-zhu, et al. Voltage Fluctuation and Flicker Caused by Wind Power Generation [J]. Power System Technology. 2003, 27(12):63-70.

[4] WU Yi-chun, DING Ming. Simulation Study on Voltage Fluctuations and Flicker Caused by Wind Farms [J]. Power System Technology. 2009, 33(20): 125-130.

[5] LIU Xiaolin. Analysis of wind turbines major types and application technology [J]. Electrical Manufacturers, 2009(09): 18-20.

[6] CHI Yongning, Liu Yanhua, Wang Weisheng, et al. Study on Impact of Wind Power Integration on Power System [J]. Power System Technology. 2007, 31(3):77-81.

[7] HU Wenjin, Wu Zhigang, Zhang Yao, et al. Analysis and Evaluation on the Electric Power Quality of Wind Farm [J]. Proceedings of the CSU-EPSA, 2009, 21(4): 82-87.

[8] HUANG Yongwei, LIU Jun, ZHOU Xichao. Simulation analysis of power quality characteristics of wind farm and control measures [J]. Industry and Mine Automation, 2012 (8):67-70.

[9] LOU Suhua, LI Zhiheng, GAO Sujie, et al. Wind Farms Models and Its Impacts on Wind Farms Integration into Power System [J]. Power System Technology. 2007, 31(supp2): 330-334.

[10] Yuan Zhi, WANG Weiqing. Measures to Suppress the Harmonic in Wind Power Generation System [J]. Electrical Machinery Technology, 2012 (02): 53-56. 